\title{
PEMBERDAYAAN PRAKTIK MANDIRI BIDAN DALAM MENINGKATKAN PENGALAMAN PERSALINAN YANG POSITIF MELALUI SOSIALISASI REKOMENDASI WORLD HEALTH ORGANIZATION (WHO) INTRAPARTUM CARE FOR POSITIVE CHILDBIRTH EXPERIENCE
}

\author{
Apri Sulistianingsih ${ }^{1}$, Dzul Istiqomah Hasyim ${ }^{2}$ \\ ${ }^{1}$ Fakultas Kesehatan, Universitas Muhammadiyah Pringsewu \\ ${ }^{2}$ Fakultas Kesehatan, Universitas Muhammadiyah Pringsewu \\ Email : sulistianingsih.apri@umpri.ac.id
}

\begin{abstract}
Abstrak : Pemberdayaan Praktik Mandiri Bidan Dalam Meningkatkan Pengalaman Persalinan Yang Positif melalui Sosialisasi Rekomendasi World Health Organization (WHO) Intrapartum Care For Positive Childbirth Experience. Asuhan persalinan selalu berkembang dari waktu ke waktu. banyaknya asuhan persalinan tertuang dalam bukti evidence based. Namun demikian tidak semua hasil penelitian di rekomendasikan untuk dilaksanakan. World Health Organization (WHO) telah menerbitkan katalog yang merekomendasikan asuhan persalinan untuk meningkatkan pengalaman persalinan yang positif yang telah di review sehingga menjadi pedoman pelaksanaan asuhan untuk seluruh dunia. Sayangnya katalog masih berbahasa Inggris dan belum banyak di ketahui terutama di Praktik Mandiri Bidan Kabupaten Pringsewu. Kabupaten Pringsewu merupakan salah satu Kabupaten di Lampung dengan kondisi kultur yang masih pedesaan. Bidan sebagian besar adalah lulusan D III yang belum mempelajari asuhan kebidanan berbasis bukti sehingga belum terpapar Rekomendasi World Health Organization (WHO) Intrapartum Care For Positive Childbirth Experience. Bentuk kegiatan berupa sosialisasi rekomendasi apasaja dalam persalinan dan apa saja yang tidak direkomendasikan dalam persalinan. Pengabdian Masyarakat dilakukan dengan menggunakan daring karena adanya pandemi covid 19 di Indonesia dan seluruh dunia. Proses pelaksanaannya menggunakan zoominar. Hasil Pengabdian didapatkan pengetahuan tentang WHO intrapartum Care For Positive Experience sebelum kegiatan adalah 60,71 (2,53), dan setelah penelitian adalah 85,3 (1,68). Hasil uji statistik menunjukkan $p$ value $=0,000$ yang berarti bahwa ada Pemberdayaan Praktik Mandiri Bidan Dalam Meningkatkan Pengalaman Persalinan Yang Positif melalui Sosialisasi Rekomendasi World Health Organization (WHO) Intrapartum Care For Positive Childbirth Experience Di Kabupaten Pringsewu
\end{abstract}

Kata Kunci : Kelas Ibu Hamil, Perisapan Persalinan, Covid 19

\section{Pendahuluan}

Bidan merupakan perempuan terdepan dalam pelayanan ibu dan anak terutama pada saat proses persalinan. Bidan menolong persalinan dalam asuhan kebidanan pada ibu bersalin sesuai dengan materi yang dipelajari pada saat perkuliahan. (King et al., 2019) Oleh sebab itu bidan yang telah lama lulus dari perkuliahan perlu mendapatkan informasi update asuhan persalinan. Sayangnya, tidak semua bidan dapat mengakses informasi pengetahuan terbaru dari dunia terutama yang berbahasa Inggris.

Kegiatan Update informasi kebidanan biasanya dilakukan melalui seminar atau pelatihan rutin berupa midwifery update $(M U)$. Namun demikian hal ini dilakukan setiap lima tahun sekali sehingga waktu terlalu lama. Untuk kegiatan seminar saat ini dilakukan kegiatan webinar pada masa pandemic Covid 19.(Kemendagri, 2020). Namun demikian tidak semua bidan mendapatkan informasi update webinar tentang persalinan. Sampai saat ini belum ada kegiatan ilmiah yang membahas tentang rekomendasi persalinan dari WHO berdasarkan evidence based.

Adanya pandemi Covid 19 ini membuat pemerintah untuk menerapkan kebijakan social distancing sejak 16 Maret 2020. (KEMENKES, 2020) Hal ini menambah keterbatasan bidan untuk mendapatkan informasi update persalinan. Dampaknya bidan akan kesulitan mengakses 


\section{BAGIMU NEGERI : JURNAL PENGABDIAN MASYARAKAT \\ P-ISSN : 2548-8651 | E-ISSN : 2548-866X \\ Email : ejournal@umpri.ac.id}

informasi update persalinan terutama sesuai dengan evidence based. (Luyben, Fleming and Vermeulen, 2020)

Masih kurangnya update asuhan persalinan dapat membuat bidan memberikan asuhan persalinan secara konvensional dan tidak mengikuti bukti penelitian terkini dapat mengurangi pengalaman persalinan dan membuat persalinan masih menakutkan bagi ibu bersalin.

Saat ini pasien lebih kritis dalam setiap asuhan diterimanya. Hal ini disebabkan oleh derasnya informasi melalui media massa baik dari social media maupun dari jurnal kesehatan. Bila bidan tidak mendapatkan informasi yang lebih baik dari pasiennya akan berdampak terhadap kepuasan ibu bersalin yang bersalin di praktik mandiri bidan.

Banyaknya jurnal penelitian tentang asuhan persalinan terkini belum tentu memiliki bukti evidence yang dapat direkomendasikan. Diperlukan systematic review hasil penelitian untuk memastikan apakah dapat diterapkan di masyarakat luas. Oleh sebab itu World Health Organization (WHO) melakukan kajian sistematis untuk memberikan rekomendasi asuhan persalinan yang dapat meningkatkan pengalaman positif ibu bersalin.(WHO, 2018)

WHO Intrapartum Care For Positive Childbirth Experience merupakan katalog rekomendasi dari WHO yang baru terbit tahun 2019. Pada katalog ini, WHO memberikan banyak rekomendasi dan larangan yang sesuai dengan evidence based terbaru. Sayangnya katalog ini berbahasa Inggris yang menyebabkan bidan di Kabupaten Pringsewu akan sulit untuk memahami dan mengakses secara rutin.

Berdasarkan hal diatas maka, Universitas Muhammadiyah Pringsewu sebagai satuan pendidikan yang merupakan sumber akses pendidikan awal kebidanan wajib untuk berkontribusi memberikan pengetahuan baru tentang persalinan berdasarkan evidence based. Salah satu tugas tri dharma dosen adalah dengan memberikan pengabdian kepada masyarakat. Pengabdian masyarakat ini ditujuan kepada bidan praktik mandiri agar dapat mengangkes informasi persalinan rekomendasi dari WHO yang diharapkan memberikan pengalaman positif persalinan pada ibu bersalin.

\section{Metode}

Kegiatan pengabdian masyarakat ini dilaksanakan secara sistematis dan tersetruktur. Bentuk kegiatan berupa sosialisasi rekomendasi apasaja dalam persalinan dan apa saja yang tidak direkomendasikan dalam persalinan. Pengabdian Masyarakat dilakukan dengan menggunakan daring karena adanya pandemi covid 19 di Indonesia dan seluruh dunia. Selain Bidan Praktik Mandiri (PMB) yang dilibatkan dalam kegiatan Pengabdian kepada masyarakat ini. Mahasiswa juga ikut terlibat dalam pelaksanaan kegiatan ini. Adapun Mahasiswa yang terlibat dalam kegiatan pengabdian kepada masyarakat ini adalah mahasiswa semester III tingkat dua yang telah mengikuti mata kuliah asuhan kebidanan ibu bersalin dan bayi baru lahir, sehingga mereka telah memiliki bekal tentang asuhan kebidanan tersebut. Dengan demikian diharapkan dapat berkontribusi nyata pada saat pelaksanaan kegiatan. Selain berperan di saat pelaksanaan, mahasiswa juga sangat berperan pada tahap persiapan pra pelaksanaan dan juga saat melakukan evaluasi pada proses kegiatanWaktu pelaksanaan kegiatan pengabdian kepada masyarakat ini dilaksanakan pada 17-20 November 2020 pukul 09-00 s/d selesai yang bertempat di F.Kes Universitas Muhammadiyah Pringsewu dengan menggunakan zoom meeting. Evaluasi dilakukan pada tahap akhir dari kegiatan. Evaluasi diberikan dengan mengumpulkan data yang diperoleh dari masing-masing kegiatan. Sebagai bentuk penilaian terhadap hasil pelaksanaan yang telah kami lakukan maka 


\section{BAGIMU NEGERI : JURNAL PENGABDIAN MASYARAKAT \\ P-ISSN : 2548-8651 | E-ISSN : 2548-866X \\ Email : ejournal@umpri.ac.id}

kami melakukan evaluasi dalam bentuk evaluasi struktur dan peran kegiatan.

\section{Hasil Dan Pembahasan}

Hasil

\section{a. Karakteristik responden}

Tabel 1 Karakteristik Responden berdasarkan Umur

\begin{tabular}{cllll}
\hline Umur & Mean (SD) & Median & Minimum & Maksimum \\
\hline & $36,36(0,71)$ & 30 & 29 & 51 \\
\hline
\end{tabular}

Pada tabel diatas dijelaskan bahwa rata-rata umur responden adalah 36,36(0,71) Tahun, dengan umur minimal 29 tahun dan umur maksimal 51 tahun.

\section{b. Pendidikan}

Tabel 2. Distribusi Responden Berdasarkan Pendidikan

\begin{tabular}{ccc}
\hline Pendidikan & N & $\%$ \\
\hline D III & 2 & 11,8 \\
D IV & 10 & 58,8 \\
S2 & 5 & 29,4 \\
& 17 & 100 \\
\hline
\end{tabular}

Hasil kegiatan pengabdian kepada masyarakat didapatkan bahwa sebagian besar tingkat pendidikan peserta pelatihan adalah D IV Kebidanan 58,8\%. Sedangkan untuk tingkat pendidikan terendah adalah Pendidikan Diploma III yaitu sebesar 11,8 \%.

c. Pengetahuan Sebelum dan sesudah penjelasan $\mathrm{WHO}$ intrapartum Care For Positive Experience

Tabel 3. Pengetahuan Sebelum dan sesudah penjelasan WHO intrapartum Care For Positive Experience

\begin{tabular}{lccc}
\hline Keterampilan & Pre test & $\begin{array}{c}\text { Kontrol }(\mathbf{n}=\mathbf{3 0}) \\
\text { Post test }\end{array}$ & Nilai $\boldsymbol{\rho}$ \\
\hline Mean (SD) & $60,71(2,53)$ & $85,3(1,68)$ & $0,000^{*}$ \\
Median & 60,0 & 85.00 & \\
Rentang & $6-12$ & $24-27$ & \\
\hline
\end{tabular}

Keterangan uji : *) T paired Test

Berdasarkan tabel 3 didapatkan pengetahuan tentang WHO intrapartum Care For Positive Experience sebelum kegiatan adalah 60,71 (2,53), dan setelah penelitian adalah 85,3 $(1,68)$. Hasil uji statistik menunjukkan $p$ value $=0,000$ yang berarti bahwa ada Pemberdayaan Praktik Mandiri Bidan Dalam Meningkatkan Pengalaman Persalinan Yang Positif melalui Sosialisasi Rekomendasi World Health Organization (WHO) Intrapartum Care For Positive Childbirth Experience Di Kabupaten Pringsewu. 


\section{BAGIMU NEGERI : JURNAL PENGABDIAN MASYARAKAT \\ P-ISSN : 2548-8651 | E-ISSN : 2548-866X \\ Email : ejournal@umpri.ac.id}

\section{Pembahasan}

Jika diamati dari tingkat usia maka secara keseluruhan responden pada kegiatan pengabdian kepada masyarakat ini sudah berada pada posisi dewasa, sehingga kedewasaan ini memberikan pengaruh terhadap peningkatan keterampilan pada kader. Usia mempunyai kaitan dengan tingkat kedewasaan seseorang yang berarti kedewasaan teknis dalam arti keterampilan melaksanakan tugas maupun kedewasaan psikologi. Usia juga terkait dengan kedewasaan berfikir, individu dengan usia dewasa mempunyai pengetahuan yang lebih baik dibandingkan dengan usia yang jauh lebih muda. Usia yang dewasa juga membuat orang mempunyai cara pandang yang matang, lingkungan sosial budaya akan membentuk pengalaman baru pada seseorang.(Himmawan, 2020)

\section{Simpulan Dan Saran}

Kegiatan kelas ibu hamil untuk mempersiapkan persalinan merupakan suatu sarana bagi dosen mahasiswa, dan masyarakat untuk menjembatani teori tentang asuhan kebidanan menjelang persalinan. Kegiatan ini dapat memfasilitasi mahasiswa untuk belajar memberikan edukasi yang tepat langsung pada ibu hamil. Sedangkan pada ibu hamil mendapatkan pengetahuan langsung oleh tenaga kesehatan untuk meningkatkan pengetahuan tentang persiapan persalinan. Diharapkan kedepannya kegiatan kelas ibu hamil di masa pandemic covid 19 ini dapat terus berlanjut dengan tetap menerapkan protocol kesehatan, sehingga pengetahuan tentang persiapan persalinan tetap didapat oleh ibu hamil meskipun pada masa pandemic covid 19.

Hasil kegiatan pengabdian kepada masyarakat didapatkan bahwa sebagian besar tingkat pendidikan peserta pelatihan adalah D IV Kebidanan 58,8\%. Sedangkan untuk tingkat pendidikan terendah adalah Pendidikan Diploma III yaitu sebesar 11,8 \%.

Teori yang menyatakan bahwa pendidikan berarti bimbingan yang diberikan seseorang kepada orang lain terhadap suatu hal agar mereka dapat memahami. Tidak dapat dipungkiri bahwa makin tinggi pendidikan seseorang semakin mudah pula mereka menerima informasi, dan pada akhirnya makin banyak pula pengetahuan yang dimilikinya. Sebaliknya, jika seseorang tingkat pendidikannya rendah, akan menghambat perkembangan sikap seseorang terhadap penerimaan, informasi dan nilai-nilai yang baru diperkenalkan (Notoatmodjo, 2016)

Berdasarkan tabel 3 didapatkan pengetahuan tentang WHO intrapartum Care For Positive Experience sebelum kegiatan adalah 60,71 (2,53), dan setelah penelitian adalah 85,3 (1,68). Hasil uji statistik menunjukkan $p$ value $=0,000$ yang berarti bahwa ada Pemberdayaan Praktik Mandiri Bidan Dalam Meningkatkan Pengalaman Persalinan Yang Positif melalui Sosialisasi Rekomendasi World Health Organization (WHO) Intrapartum Care For Positive Childbirth Experience Di Kabupaten Pringsewu

Peningkatan pengetahuan tidak mutlak diperoleh di pendidikan formal, akan tetapi juga dapat diperoleh pada pendidikan non formal. Pada tahap ini Sebagian besar responden adalah Pendidikan D IV Kebidanan. Hal ini berarti bahwa responden telah mendapatkan akses untuk melihat penelitian-penelitian terkini pada persalinan. Seseorang dengan tingkat pendidikan rendah tidak berarti mutlak berpengetahuan rendah pula dan seseorang dengan tingkat pendidikan tinggi tidak berarti mutlak berpengetahuan baik pula. Pendidikan adalah suatu kegiatan atau proses pembelajaran untuk mengembangkan atau meningkatkan kemampuan tertentu sehingga sasaran pendidikan itu dapat berdiri sendiri. Akan tetapi tingkat pendidikan turut pula menentukan mudah tidaknya seseorang dalam menyerap dan memahami 


\section{BAGIMU NEGERI : JURNAL PENGABDIAN MASYARAKAT \\ P-ISSN : 2548-8651 | E-ISSN : 2548-866X \\ Email : ejournal@umpri.ac.id}

pengetahuan yang mereka peroleh, pada umumnya semakin tinggi pendidikan seseorang semakinbaik pula pengetahuanya.

\section{Daftar Rujukan}

Himmawan, L. S. (2020) 'Faktor Yang Berhubungan Dengan Pengetahuan Kader Posyandu Tentang 1000 Hari Pertama Kehidupan (Hpk)', Jurnal Kesehatan, 11(1), pp. 1408-1414. doi: 10.38165/jk.v11i1.194.

Kemendagri (2020) Pedoman Manajemen Bagi Pemerintah Daerah Dalam Penanganan Covid 19 dan Dampaknya. Jakarta: Kementerian Dalam Negeri Republik Indonesia.

KEMENKES (2020) Pedoman Bagi Ibu Hamil, Ibu Nifas, dan Bayi Baru Lahir Di Era Pandemi Covid-19. Jakarta: KEMENTERIAN KESEHATAN RI. Learning.

King, T. L. et al. (2019) Varney's Midwifery. Burilington: World Headquarters Jones \& Bartlett

Luyben, A., Fleming, V. and Vermeulen, J. (2020) 'Midwifery education in COVID-19- time: Challenges and opportunities', Midwifery, 89. doi: 10.1016/j.midw.2020.102776.

Notoatmodjo (2016) Promosi kesehatan dan perilaku kesehatan.

WHO (2018) WHO Recommendations Intrapartum care for a positive childbirth experience. Available at: http://apps.who.int/iris/bitstream/10665/260178/1/9789241550215eng.pdf?ua=1\%0Ahttp://www.who.int/reproductivehealth/publications/intrapartum-care-

guidelines/en/.

Bowo, I., ... A. S.-P. S., \& 2021, undefined. (2021). Sosialisasi Uji Etik Penelitian Kesehatan Mahasiswa Berbasis IT di Universitas Muhammadiyah Pringsewu. Jurnal.Darmajaya.Ac.Id, $13-17$. https://jurnal.darmajaya.ac.id/index.php/PSND/article/view/2924 